\title{
Медиаобразование школьников в России: от протоформатов к консенсуальному подходу
}

Даниил Лапин

Статья представляет собой исторический анализ основных этапов развития медиаобразования школьников в России: от практико-утилитарной и воспитательно-эстетической концепций к современной социокультурной модели. Значительное внимание уделяется кинообразованию и информационной грамотности как предшественникам медиаобразования, сформировавшим актуальные сегодня педагогические практики. Как возможная для объединения данных сфер предлагается модель медиаобразования, состоящая из трех этапов: критического восприятия, аналитического осмысления и творческого воспроизведения.

Ключевые слова: медиаобразование, медиаграмотность, кинообразование, информационная грамотность, консенсуальный подход.

DOI: 10.30547/mediaalmanah.6.2020.2231

@ Лапин Даниил Андреевич аспирант кафедры теории и экономики СМИ факультета журналистики МГУ имени М.В. Ломоносова (г. Москва, Россия), dmglapin@gmail.com

\section{Введение}

Одной из ключевых составляющих повседневной жизни человека сегодня являются медиа: благодаря им индивиды не только потребляют, но и производят и распространяют контент, осуществляют коммуникацию, приобретают новые навыки и компетенции. Медиа постепенно становятся теми самыми «внешними расширениями человека», о которых писал Г.М. Макклюэн (2003), и, возможно, внешними расширениями всего общественного пространства. Усложняющийся процесс медиакоммуникации, различная степень вовлеченности аудитории на разных этапах потребления и создания контента требуют не только нового теоретического понимания медиа, но и конкретных мер по обеспечению «здоровой» цифровой медиакоммуникационной среды (Вартанова, Фролова (ред.), 2018: 6). Более того, становится важным переосмысление теоретических основ медиа и практического их воплощения в профессиональном и общественном контекстах.

На первый план сегодня выходит медиаобразование как образовательно-практический комплекс, позволяющий индивиду подготовиться к взаимодействию с медиа, приобрести навыки, помогающие критически воспринимать, аналитически осмыслять и творчески воспроизводить медиаконтент. Однако медиаобразование, результатом 
которого является медиаграмотность, опирается на солидный теоретико-практический базис, сформированный исследователями протоформатов медиаобразования (кинообразования и информационной грамотности), которые, в свою очередь, придавали медиаобразованию соответственно либо педагогическую, либо информационно-технологическую направленность. В рамках данной статьи автором предпринята попытка на основании исторического анализа протоформатов медиаобразования предложить современный подход к медиаобразованию с учетом особенностей влияния медиа на общество и индивида сегодня.

Прежде чем перейти к историческому анализу, определимся страктовкой основных понятий данной статьи: кинообразование, информационная грамотность, медиаобразование и медиаграмотность.

«Кинообразование - процесс образования и развития личности средствами и на материале киноискусства с целью формирования культуры общения с экраном, творческих, коммуникативных способностей, умений интерпретации, анализа и оценки кинотекста, обучения различным формам самовыражения при помощи кинотехники» (Федоров, 2015: 18).

«Информационная грамотность - наличие знаний и умений идентификации информации, необходимой для выполнения определенного задания или решения проблемы, эффективного поиска информации, ее организации и реорганизации, интерпретации и анализа найденной и извлеченной информации; оценки точности и надежности информации, включая соблюдение этических норм и правил пользования полученной информацией; при необходимости передачи и представления результатов анализа интерпретации другим лицам; последующего применения информации для осуществления определенных действий и получения определенных результатов» (Гендина, 2007: 61).
«Медиаобразование - комплекс образовательных и просветительских программ, направленный на изучение природы и особенностей функционирования медиа с целью повышения уровня медиаграмотности аудитории, развития критического восприятия, аналитического мышления и творческих навыков, а также формирования навыков безопасного поведения в цифровой медиасреде» (Вартанова (ред.), 2019: 137).

«Медиаграмотность - тип грамотности, приобретаемый в результате освоения программ медиаобразования. Развитие и повышение медиаграмотности - главная задача медиаобразования. Медиаграмотность предполагает усвоение знаний о природе и основных принципах медиакоммуникаций в современном обществе; об информационных и медиакоммуникационных технологиях; направлена на развитие способности к анализу и оценке содержания информации, ее критическому осмыслению, а также умение использовать эту информацию осознанно» (Вартанова (ред.), 2019: 114).

В силу многогранности развития медиаобразования каждое из приведенных определений может считаться составляющей комплексного определения медиаобразования в XXI в., что позволит современным исследователям из разных научных сфер прийти к консенсуальному пониманию медиаобразования, объединив кинообразование в интерпретации А.В. Федорова как способ формирования культуры общения с экраном (в эпоху информационного фастфуда), информационную грамотность в прочтении Н.И. Гендиной - как метод развития навыков по поиску, организации и анализу информации, медиаграмотность и медиаобразование в определении Е.Л. Вартановой - как комплекс образовательных и просветительских программ, направленных на формирование знаний о природе и принципах медиакоммуникации и медиакоммуникационных технологий. 


\section{Кинообразование}

Социокультурная направленность медиаобразования формировалась поэтапно в ходе развития педагогической науки и разработки новых педагогических практик и их интеграции с информационной грамотностью. Отечественная история медиаобразования берет свое начало в кинообразовании. Первые исследования о влиянии средств массовой коммуникации, прежде всего кино, появлялись в России в начале XX в. Вследствие нарастающей популярности кино педагогика предпринимала первые попытки в реализации его воспитательной и образовательной функций. Уже в 1914 г. указывалось, что при «правильном использовании» кинематограф имеет возможность стать одним из учебно-воспитательных пособий для будущих поколений. Исследователи предпринимали попытки дать психологическое обоснование преимуществам этого дидактического средства обучения. Обосновано это было тем, что с 1917 г. кинематограф стал доступен для школьников (до этого момента посещение кинотеатров для детей было под запретом).

На первых этапах развития киноискусства подспорьем для эстетического образования школьников могли служить работы отечественных философов: В.С. Соловьева (1991), Н.А. Бердяева (1989) и многих других, однако их труды не были восприняты массами в силу своей религиозной и антисоциалистической направленности. Основной акцент делался на пропагандистскую, просветительскую и развивающую функции кинематографа для детей. После 1920 г., в результате популяризации кино в молодежной среде, начала реализовываться идея его интеграции в учебные процессы, и были созданы первые программы приобщения школьников к киноискусству.

Важной вехой в процессе развития кинообразования стал 1927 г.: принято решение о внедрении курса «по киноработедля детей» (Постановление коллегии Народного комитета просвещения «О разработке мероприятий по детскому кино» (Федоров, Челышева, Мурюкина, Горбаткова и др., 2014)), открылись первые краткосрочные курсы кинопедагогов. Институтом методов внешкольной работы была поставлена задача по выработке организационных форм, наполнения и методов массовой работы сдетьми в кино. Одной из главных целей для кинопедагогов стало воспитание в детях более глубокого отношения $\mathrm{k}$ кино как к искусству. Кинематограф для педагогов 1920-1930 гг. приобретал черты не просто учебного пособия, а искусства с огромными возможностями воспитательного воздействия (Парамонова, 1962: 20). Идеи медиапедагогики данного периода легли в основу воспитательно-эстетических моделей медиаобразования вплоть до начала XXI в.

\section{Практико-утилитарная концепция (1935-1955 гг.)}

В эпоху тоталитаризма на первый план вышла ориентация на прикладной характер художественного образования: обучение техническим навыкам, изобразительно-иллюстративным навыкам, а также коллективное обсуждение полученных результатов. Вопросы аналитического восприятия, критического мышления и эстетического воспитания (столь популярные в современной медиапедагогике) отошли на второй план.

Период медиапедагогической деятельности с 1935 по 1955 гг. А.В. Федоров (2015: 127) называет регрессом, так как, по его мнению, в обозначенный период преобладала ярко выраженная практическая направленность, а педагогические практики в кинообразовании были подчинены следованию идеалам соцреализма. Сокращалось количество кино- и фотокружков, уменьшалась доля поддержки, оказываемой государством профессиональным вузам, на первый план выступали идеологические задачи и обучение школьников работе с аудиовизуальной техникой, не использовались труды исследователей 
1920 гг. Однако стоит отдать должное практической работе, которая велась в указанный период и стимулировала самостоятельную работу школьников (съемка документальных фильмов, фотография, участие в конкурсах).

Также в рамках данного периода необходимо отметить разведение литературы и кинематографа как разных видов искусства в сознании учащихся, чтобы они не подменяли прочтение книг их экранизациями. Идеологическая направленность образования оказывала влияние и на работу с детьми в рамках школьной прессы. «Дети для этих изданий играли роль пассивного объекта воспитания, послушных исполнителей приказов взрослых", - пишет А.В. Федоров (2015: 131). Школьная пресса представляла собой стенгазеты, фото- и радиогазеты, световые и живые издания, получившие в те годы широкое распространение. «Задачи школьной печати в работах тех лет виделись в том, чтобы помогать учителям, комсомольской и пионерской организации сплачивать учащихся в дружные, целеустремленные классные и общешкольные коллективы, бороться за высокую успеваемость, сознательную дисциплину и активное участие в работе всех школьников, развивать в ученическом коллективе критику и самокритику, воспитывать высокоидейное общественное мнение», - отмечает А.Н. Капралова (1949: 13). Школьная пресса представлялась скорее ментором или судьей, чем другом и советчиком (Федоров, 2015: 131).

Воспитательное воздействие печати на детей зиждилось на следующих составляющих: коммунистическая идейность, правдивость и точность, плановость и регулярность выпуска, злободневность и разносторонность тематики и содержания, острая форма подачи и яркость оформления, массовое участие обучающихся в подготовке материалов, согласованность в работе редколлегий периодических изданий (Колдунов, 1955: 249-250).
Что касается медиаобразования на материале прессы, то в этой сфере развитие получило движение юнкоров, так как «правительство активно способствовало этому процессу, преследуя две основные цели: широкое распространение коммунистической идеологии; ликвидацию неграмотности населения» (Шариков, 1990: 125-126). Юные корреспонденты создавали материалы в самых разных условиях: участвуя в уборке урожая, экспедициях и т.п. «Наблюдается появление десятков газет и журналов, создаваемых разного рода организациями школьников, союзами молодежи» (Шариков, 1990: 125).

\section{Эстетическая концепция (1956-1968 гг.)}

Следующей вехой развития отечественного медиаобразования считается период «оттепели» (1956-1968 гг.). Педагогика проходила процесс либерализации, активно развивалось движение кинообразования. Эстетическое воспитание начало рассматриваться педагогами как средство гармонического развития человека, приобщения его к искусству, освоения художественного языка и формирования образного мышления; свое продолжение нашли гуманистические идеи исследователей XIX в. В этот период развернулась активная деятельность классиков отечественного медиаобразования: О.А. Баранова, С.Н. Пензина, Ю.М. Рабиновича, Ю.Н. Усова (Федоров, 2015: 133). Впервые фокус исследователей обратился на особенности восприятия детской аудитории, работу с близким школьникам материалом, поэтапное погружение обучающихся в киноискусство. Вместе с этим отечественные педагоги пытались найти взаимосвязи между литературой и кино, стремясь внедрить его в школьный образовательный процесс по причине увеличения интереса молодежи именно к кинематографу и нежелания школьной системы видоизменять образовательную программу. В исследованиях того времени, 
посвященных кинообразованию, уже выкристаллизовывались задачи, которые впоследствии стали задачами медиаобразования: развитие самостоятельного критического мышления, а также воображения в рамках творческой работы обучающихся.

Стоиттакже отметить, что в 1960 гг. отечественное медиаобразование начало работать на материале телевидения, постепенно вытеснявшего кинематограф с пьедестала любимца аудитории. Обсуждались образовательные возможности телевидения, его роль в художественном воспитании общества. Предлагалось начать работу «по выработке вкуса, по привитию детям определенных знаний» (Строева, 1962: 20). Вести подобную работу предположительно перед просмотром передачи или фильма должны были представители старшего поколения в семьях (возможно, именно в данной концепции берет свое начало конфликтный треугольник современного медиаобразования: родители, школа, дети). Необходимость ведения такой работы обосновывалась непредсказуемой силой воздействия телевидения на аудиторию, опасениями за вкусы зрителей после просмотра шаблонных, легковесных программ (Пензин, 1967: 21-22). Несмотря на это, медиаобразовательный потенциал телевидения практически не использовался в школах и вузах, в отличие от радио и прессы (школьники вовлекались в творческую работу редакций периодических изданий, создавали собственные радиовыпуски и т.д.).

\section{Развитие эстетической концепции (1969-1985 гг.)}

Период оттепели завершился. Власть снова взяла курс на усиленную идеологизацию жизни в стране, однако политические лозунги и акции воспринимались обществом, и в том числе медиапедагогами, критичнее, что привело к попыткам «отгородиться от идеологического напора за своеобразным художественным барьером» (Федоров, 2015: 152). В результате,
1969-1985 гг. стали периодом расцвета эстетически ориентированного кинообразования. Педагоги еще больше углубились в изучение личности ребенка: вместе со вкусами и предпочтениями детей в кинематографе изучались их возрастные и психологические особенности, вопросы взаимодействия детской аудитории с экраном. Разрушался старый подход, в котором учитель является источником информации, а учащийся простым реципиентом, предпринимаются попытки наладить диалог (Вайсфельд, 1993: 4-5). Однако стоит отметить, что образовательный процесс еще не сочетал в себе практическую и эстетическую работу: два этих направления существовали и развивались автономно друг от друга, разнились методически. В кинообразовательный процесс того времени внедряется усиленная работа над составляющими кинематографа (сценарий, особенности съемки и монтажа). Эта деятельность со временем перешла к теоретическим обобщениям. Важно подчеркнуть, что «воспитательные возможности киноискусства стали общепризнанным фактом» (Федоров, 2015: 155).

Ю.Н. Усов (1980: 4-5) вывел формулу процесса восприятия экранного произведения (впоследствии использовалась как формула восприятия медиатекста) как «установление ассоциативной связи с конкретным художественным и жизненным опытом зрителя, интуитивное постижение пластических форм в результате сопереживания с героем и автором, возникновение образных обобщений отдельных составляющих фильма» и сформулировал понятие аудиовизуальной грамотности как культуры восприятия звукозрительного образа, включающей умение его анализа и синтеза.

Большая часть отечественных исследований кинообразования посвящалась максимальному использованию воспитательных возможностей художественного кино в социальном формировании школьников. Уделялось внимание одной из основных 
проблем - низкому уровню художественного восприятия обучающихся. Вместе с этим увеличился интерес исследователей к проблеме детского творчества, связанного с медиа, начался процесс выявления психологических и социологических пластов образования. В 1970-1980 гг. аналитики медиаобразования также отмечали стихийность взаимодействия школьников с телевидением и радио, отсутствие педагогического контроля за этим процессом. Кроме того, наравне с этим вопросом обозначалась и проблема неподготовленности большинства педагогов к осуществлению подобного контроля и реализации медиаобразовательного процесса на материале радио и телевидения. В сфере школьной печатной журналистики помимо продолжения работы юнкоровских объединений возникла и распространилась практика интеграции детской и взрослой печати (создание детской редакции при редакции периодических изданий).

Стоит также отметить, что в 1970 гг. сотрудниками библиотек впервые в отечественной практике разрабатывается термин «информационная культура» (Гендина, 2007: 63), который развивался впоследствии в контексте информационной подготовки граждан.

\section{Социокультурная концепция (1986-2000 rr.)}

В период перестройки, когда телевидение становилось более доступным для домашнего использования, были созданы «идеальные условия для поверхностного восприятия художественных произведений, увлечения массовой аудиторией лишь теми медиатекстами, которые в меньшей степени требовали от зрителя искусствоведческих знаний и аналитических умений» (Федоров, 2015: 183).

Сменились и педагогические подходы. Как наиболее эффективный и перспективный подход на первом месте закрепился диалог между учителем и учеником. Вместе с этим увеличивалась вариативность методик преподавания, к занятиям в школах активно привлекалась мультипликация, использовался кинематограф в школьных кинотеатрах, киноискусство было включено в курсы литературы (Вайсфельд, 1988: 9-11). Медиа воспринимались педагогами как необходимая составляющая гармоничного развития личности, однако все еще лишь как составляющая, а не возможность для комплексного развития. В целом это можно расценивать как противовес западной медиапедагогике, направленной на развитие личности в медиасреде (формирование критического мышления, защита от негативного влияния медиа, а также развитие вкуса и чувства прекрасного). Но отечественные эксперты продолжали настаивать именно на творческом развитии личности через воспитательно-эстетическую работу: проводились исследования, посвященные последовательному развитию личности, перцептивным особенностям школьников и особенностям развития кинограмотности. Кинообразование воспринималось педагогами как средство активизации социализации школьников при использовании метода общения на основе киноискусства, позволяющее учащимся через мир ценностей уточнить свои жизненные позиции и отношение к труду и обществу (Усов, 1998: 3).

Важной вехой стоит считать работу А.В. Шарикова «Медиаобразование: мировой и отечественный опыт» (1990), в которой медиаобразование наконец было описано как комплексный конструкт, включающий в себя и телевидение, и радио, и прессу, и кинематограф, а также фотографию, звукозапись, рекламу и многое другое, показаны причины возникновения медиаобразования. Определены три ключевые его концепции: медиаграмотность, информационная защита и социально-педагогическая концепция. А.В. Шариков отмечает, что медиаобразование опиралось на многолетний опыт кинообразования. Однако 
важным видится заключение исследователя о том, что обучать школьников «языку кино» без понимания всей системы социокультурных связей в процессе коммуникации было недостаточно для полноценного воспитания гражданских качеств (Шариков, 1990: 6). Медиаобразование помогло педагогам найти выход из этого положения. Они сместили акцент на развитие медиакоммуникативных, творческих способностей учащихся, сохраняя традиции воспитательно-эстетического подхода. Медиаобразование было разделено на два основных направления: образование на материале СМИ (газет, журналов, радио, телевидения) и образование на киноматериале. На сегодняшний день в отечественной практике оба направления терминологически обозначены как медиаобразование, однако в рамках данной статьи мы ориентируемся на более актуальное определение, данное во введении.

Во второй половине 1980 гг. педагоги активно изучали влияние телевидения на школьников (Спичкин, 1999; Шариков, 1989) и его возможности в воспитании подрастающего поколения. Вместе с новым направлением развивалось и медиаобразование на материале прессы: детская печать отделялась от взрослых изданий, появлялись самостоятельные детские редакции в российских городах (Томск, Новосибирск, Кострома и др.), активно разворачивало деятельность детско-юношеское агентство ЮНПРЕСС (проведение международных фестивалей и конференций, посвященных детской прессе, публикация учебно-методической литературы и т.д.). Работа с юнкорами строилась на установлении взаимного диалога между преподавателями и школьниками.

В период 1990-2010 гг. медиаисследователи отмечали, что «содержание медиатекстов изменилось под влиянием процесса коммерциализации медиа, ориентира на рейтинг и тираж, акцент сместился в сторону развлекательности и зрелищности в противовес культурно-просветительским и познавательным возможностям» (Полуэхтова, 1998: 67). Изменилась и структура отечественных медиа. В указанный период в расцвете своего влияния находилось телевидение: многочисленные игровые программы, демонстрация кинофильмов, использование мультипликации, развлекательные телешоу. Тем не менее отмечалось, что «большинство нынешних телеигр выполняет лишь гедонистическую функцию, не способствуя при этом развитию личности» (Суртаев, 2000: 142), «чрезмерное увлечение лотереями и развлекательными шоу <...> мало способствует развитию самостоятельного мышления, воображения и т.д.» (Федоров, 2015: 211).

Медиапедагоги все еще пытались внедрить медиаобразовательные практики в общеобразовательный процесс (Спичкин, 1999), однако постепенно переходили от вопросов эстетического воспитания к социокультурной концепции: «Отношение к медиаобразованию <...> может служить индикатором демократических перемен в стране, потому что переход от пассивного потребления к критическому анализу средств информации <...> зависит и от понимания роли средств массовой информации в обществе» (Спичкин, 1997: 56). В 2003 г. на факультете журналистики МГУ имени М.В. Ломоносова была разработана концепция «модуля медиаобразования" для вузов и школ страны (Вартанова, Засурский, 2003). Комплексное определение информационной грамотности, в свою очередь, также приводит к мысли о начале процесса симбиоза медиаобразования и информационной грамотности.

В 1990 гг. свои поправки в медиаобразовательные практики внес Интернет - его начали использовать в юнкоровском движении и постепенно внедрять в образовательные программы. Более того, в конце 1980 - начале 1990 гг. российские учебные заведения оснащались компьютерной техникой, был введен предмет «Информатика» 
(Федоров, 2015: 208). Таким образом, мы видим, что дисциплины, касающиеся обучения информационной грамотности и развития информационной культуры, включались в образовательный процесс в качестве обязательных. По мнению И.В. Вайсфельда (1988: 8-9), «школа вступила в эпоху компьютеризации, проводившуюся на разных уровнях:для всех и для тех, кто проявляет способности к технике». Медиаобразование было призвано выполнять уникальную функцию подготовки детей к жизни в информационном пространстве путем усиления медиаобразовательной аспектности при изучении различных дисциплин (Зазнобина, 1998).

Таким образом, можно сделать вывод, что 1990-2010 гг. стали новым этапом в развитии медиаобразования, характеризующимся переключением фокуса с воспитательноэстетической модели на социокультурную модель, обоснованную необходимостью подготовки детей к существованию в медиасреде с целью развития гражданского общества. Этот период стал также началом процесса симбиоза медиаобразования и информационной грамотности.

\section{Заключение}

На основании исторического анализа можно определить следующие этапы развития отечественных медиаобразовательных моделей: этап становления кинообразования (вера в силу воспитательно-эстетической модели), практико-утилитарный этап (необходимость обучения технологическим навыкам), эстетический (развитие воспитательно-эстетических функций) и социокультурный этап (фокус на развитие личности и подготовку школьников к эффективному существованию в социуме и медиасреде, переход к медиаобразованию).
Долгое время медиаисследователи не были полностью включены в теоретическую разработку и практическую интеграцию медиаобразовательных практик в России (данной проблемой занимались педагоги и специалисты библиотечного дела при поддержке ЮНЕСКО и ИФЛА). Только в 2010 г. вышел в свет сборник «Медиаобразование в школе» (под редакцией Е.Л. Вартановой и О.С. Смирновой), а в 2018 г. факультетом журналистики МГУ имени М.В. Ломоносова была издана коллективная монография «Медиа в образовательной среде: коммуникации и безопасность детей» (под редакцией Е.Л. Вартановой и Т.И. Фроловой).

Сегодня очевидны переход к социокультурной модели медиаобразования, его симбиоз с информационной грамотностью, усиливающееся влияние медиа на общество и все более усложняющиеся процессы медиакоммуникации, а также необходимость обучать подрастающее поколение ориентироваться в информационном потоке и медиапроцессах. В связи с этим возрастает необходимость привлечения исследователей из сферы педагогики, информационной культуры и медиа к разработке учебно-методических программ и практической их реализации на основании синтеза накопленного опыта кинообразования и информационной грамотности, на данный момент существующих практически независимо друг от друга. Как возможная для объединения данных сфер предлагается модель медиаобразования, состоящая из трех этапов: критического восприятия, аналитического осмысления и творческого воспроизведения. Это позволит, на наш взгляд, сформулировать актуальный современный консенсуальный подход к медиаобразованию.

Исследование выполнено при финансовой поддержке РФФИ и ЭИСИ в рамках научного проекта № 20-011-31329. 


\section{Библиография}

Бердяев Н.А. Философия свободы. Смысл творчества. М.: Правда, 1989.

Вайсфельд И.В. Развитие кинообразования в условиях перестройки. М.: Изд-во Общества друзей кино, 1988.

Вайсфельд И.В. Эволюция экрана, эволюция восприятия // Специалист. 1993. № 5. C. 3-6.

Вартанова Е.Л., Засурский Я.Н. Российский модуль медиаобразования: концепции, принципы, модели // Информационное общество. 2003. № 3. С. 5-10.

Гендина Н.И. Информационная грамотность и информационная культура личности: международный и российский подходы к решению проблемы // Открытое образование. 2007. № 5 (64). С. 58-69.

Гендина Н.И. Информационная культура и медиаграмотность в России // Информационное общество. 2013. № 4. С. 77-83.

Зазнобина Л.С. Стандарт медиаобразования, интегрированного с различными школьными дисциплинами // Стандарты и мониторинг в образовании. 1998. № 3. С. 26-34.

Капралова А.Н. Ежедневная школьная стенная газета. М.: АПН РСФСР, 1949.

Колдунов Я.И. Школьные газеты как средство коммунистического воспитания учащихся средней школы: дис. ... канд. пед. наук. М., 1955.

Макклюэн Г.М. Понимание медиа: Внешние расширения человека / пер. с англ. В. Николаева. М.: Жуковский: «КАНОН-пресс-Ц», «Кучково поле», 2003.

Медиа в образовательной среде: коммуникации и безопасность детей: колл. моногр. / под ред. Е.Л. Вартановой, Т.И. Фроловой. М.: Фак. журн. МГУ, 2018.

Медиаобразование в школе: сб. программ преподавания дисциплин / под ред. Е.Л. Вартановой, О.В. Смирновой. М.: МедиаМир, 2010.

Отечественная теория медиа: основные понятия. Словарь / под ред. Е.Л. Вартановой. М.: Фак. журн. МГУ; Изд-во Моск. ун-та, 2019.

Парамонова К.К. Рождение фильма для детей. М.: Изд-во ВГИК, 1962.

Пензин С.Н. Некоторые проблемы теории и практики телевизионной пропаганды киноискусства: автореф. дис. ... канд. искусств. М., 1967.

Полуэхтова И.А. Телевидение в развитии художественной культуры школьников // Содружество школы и учреждений культуры в художественном воспитании учащихся. М.: РАО МК РФ, 1998. С. 65-84.

Соловьёв В.С. Философия искусства и литературная критика. М.: Искусство, 1991.

Спичкин А.В. Государство, средства массовой информации и образование // Проблемы кинообразования в вузе и в школе / под ред. С.М. Одинцовой. Курган: Изд-во Курганск. гос. ун-та, 1997. С. 50-60.

Спичкин А.В. Что такое медиаобразование. Курган: Изд-во Ин-та повышения квалификации и переподготовки работников образования, 1999.

Строева А.С. Дети, кино и телевидение. М.: Знание, 1962.

Суртаев В.Я. Социокультурное творчество молодежи: методология, теория, практика. СПб: С.-Петербургск. гос. ун-т культуры и искусства, 2000.

Усов Ю.Н. Медиаобразование. Программа для учащихся десятого-одиннадцатого класса общеобразовательной школы // Основы экранной культуры. М.: Изд-во Рос. акад. образования, 1998. С. 55-59.

Усов Ю.Н. Методика использования киноискусства в идейно-эстетическом воспитании учащихся 8-10 классов. Таллин: Мин-во просвещения, 1980. 
Фёдоров А.В. Медиаобразование: история и теория. М.: МОО «Информация для всех», 2015.

Фёдоров А.В., Челышева И.В., Мурюкина Е.В., Горбаткова О.И. и др. Массовое медиаобразование в СССР и России: основные этапы / под ред. А.В. Федорова. М.: МОО «Информация для всех», 2014. Режим доступа: https://ifap.ru/library/book545.pdf

Шариков А.В. Возрастные особенности телевизионных ориентаций школьников: автореф. дис. ... канд. пед. наук. М., 1989.

Шариков А.В. Медиаобразование: мировой и отечественный опыт. М.: Изд-во Акад. пед. наук СССР, 1990. 